Int. J. Odontostomat., 8(2):207-210, 2014.

\title{
WaveOne: A Simple and Safe Way to Perform an Endodontic Treatment
}

\author{
WaveOne: Una Manera Simple y Segura para Lograr un Tratamiento Endodóntico
}

\author{
Daniel Aracena*; Pablo Betancourt"; Eduardo Borie ${ }^{* * *, * k *}$; Mario Guzmán ${ }^{* * * * *}$ \& Ramón Fuentes ${ }^{* * * *}$
}

ARACENA, D.; BETANCOURT, P.; BORIE, E.; GUZMÁN, M. \& FUENTES, R. WaveOne: a simple and safe way to perform an endodontic treatment. Int. J. Odontostomat., 8(2):207-210, 2014.

ABSTRACT: Variations in the root canal's anatomy play an important role on endodontic therapy success, primarily in teeth with pulp necrosis. Traditionally, the preparation of root canals was performed with the use of stainless steel hand files; but over the years, new flexible instruments were introduced to prevent or minimize iatrogenic errors in shaping the root canal system. In most of recent publications, alternating rotation movements have been proposed as an alternative to continuous rotation in order to reduce the risk of fracture of the instrument and the root canal deformation. The aim of this article was to report a clinical case describing the simple way to perform the endodontic treatment of a maxillary premolar with three root canals, with the WaveOne reciprocating system.

KEY WORDS: endodontics, root canal obturation, nickel-titanium, reciprocating movement, WaveOne.

\section{INTRODUCTION}

Variations in the root canal's anatomy of the root canals play an important role on endodontic therapy success (Chakradhar Raju et al., 2010), mainly in teeth with pulp necrosis (Favieri et al., 2006). It is very important to point out the changes in the root canals morphology in teeth requiring endodontic treatment (Oporto et al., 2010). Therefore, the clinician must be very careful when performing endodontic treatment of maxillary premolars due to extreme variability in their anatomy (Cantatore et al., 2009; Aracena et al., 2012).

Traditionally, root canal instrumentation was performed with the use of stainless steel hand files; but over the years, new flexible instruments were introduced to prevent or minimize iatrogenic errors in shaping the root canal system (Javaheri \& Javaheri, 2007). Thus, nickel-titanium (Ni-Ti) and the rotary system, reduced operator fatigue and time required to complete the canal preparation, decreasing related procedural errors with a better centering of root canals, increasing the efficiency of cutting (Yared, 2008; Gutmann \& Gao, 2012). However, the risk of the instrument's fracture was still present in these systems, so Yared, introduced a new instrumentation technique consisting in the use of a single rotary $\mathrm{Ni}-\mathrm{Ti}$ instrument with a reciprocating motion, completing the root canals shaping.

In this way, since 2011, reciprocating nickeltitanium WaveOne was introduced to the dental market. These files manufactured by heat treatment process of $\mathrm{Ni}$-Ti called M-Wire, would present greater flexibility and greater resistance to cyclic fatigue than traditional $\mathrm{Ni}-$ Ti's. In addition, as the files use a reciprocating motion, they would avoid exceeding the maximum limit of elasticity, turning up fewer fractures than classical instruments of continuous rotation.

In most of recent publications, alternating rotation movements have been proposed as an alternative to continuous rotation in order to reduce the risk of fracture of the instrument and the root canal deformation (VarelaPatiño et al., 2010). Also, most of studies found in the literature about the WaveOne system are in vitro. Hence, the aim of this article was to report a clinical case describing the simple way to perform the endodontic treatment of a maxillary premolar with three root canals with the WaveOne rotatory system.

* Escuela de Odontología, Universidad Mayor, Temuco, Chile.

* Alumno Magister en Odontología, Facultad de Odontología, Universidad de La Frontera, Temuco, Chile.

*** Dental Materials and Prosthodontics Department, Ribeirão Preto Dental School, University of São Paulo, Ribeirão Preto, SP, Brazil.

**** Facultad de Odontología, Universidad de La Frontera, Temuco, Chile.

*t*t** Departamento de Ingeniería Mecánica, Facultad de Ingeniería y Ciencias, Universidad de La Frontera, Temuco, Chile. 


\section{CASE REPORT}

A 25-year-old male patient was referred to the Dental Service of the local hospital for an endodontic treatment of tooth 2.5 . His medical history was uneventful.

At clinical examination, we observed that tooth 2.5 was symptomatic and the crown presented temporal cement. Radiographically, an extended radiolucent area involving the pulp chamber was identified, compatible with a cameral pulp extirpation (Fig. 1). The root presented three root canals and the periapical portion and periodontal ligament with no signs of abnormality.

In the treatment stage, initially the three root canals were permeabilized with \#10 and \#15 K-files (Dentsply Maillefer, Ballaigues Switzerland). The working length was determined with a periapical radiograph and verified with the aid of an electronic apex locator (Propex II, Dentsply Maillefer, Ballaigues Switzerland). After this, the canal shaping was performed by a rotatory reciprocating files (WaveOne, Dentsply Maillefer, Ballaigues, Switzerland) at $350 \mathrm{rpm}$, following the manufacturers indication, with a Crown-down technique, and checking the working length (WL) in each third of tooth preparation. This system uses an only single file Primary 025/08 in the treatment and for the three canals. In the entire canal shaping stage, the area was perfused with sodium hypochlorite at $5.25 \%$ and permeabilized with a \#15 K-file to remove the smear layer of the root canals. The stages of canal shaping and preparation with WaveOne rotatory system take a very short time.

The canal obturation was done with WaveOne points with the same taper of the Primary file, achieving a proper fit in the apex. As a final root canal sealer, TopSeal (Dentsply Maillefer, Ballaigues Switzerland) was used, helping to fill, by a lateral condensation, the spaces between the WaveOne points. Finally a radiographical (Fig. 2) and clinical control was done at 15 and 30 days after the treatment, observing no clinical symptoms or radiographical findings of treatment failure.

\section{DISCUSSION}

The canal instrumentation is a key factor for the chemo-mechanical preparation in endodontic treatments (Dietrich et al., 2012; Berutti et al., 2012; Kim et al., 2012).

The arrival of nickel-titanium (Ni-Ti) and rotary instrumentation in the clinical practice has revolutionized and improved the endodontic therapy, reducing operator fatigue, decreasing the time required to complete the preparation, and preventing some risks and procedural errors related with the straightening or centering in the root canals, increasing cutting efficiency (Yared; Gutmann \& Gao; Pédulla et al., 2011; Saber Sel \& Abu El Sadat, 2013). This rotational technique is safe and more reproducible with less procedure errors compared with the manual technique. The high elasticity of the rotatory NiTi files allow the use of less force on the canal walls, especially in highly curved canals (Peters, 2004). However, the manufacturers have recently introduced

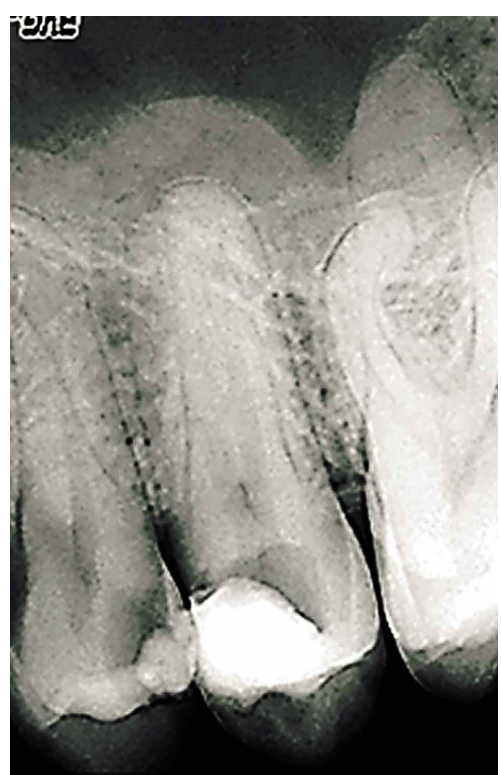

Fig. 1. Initial radiograph showing extended radiolucent area involving the pulp chamber on tooth 25 , compatible with a cameral pulp extirpation.

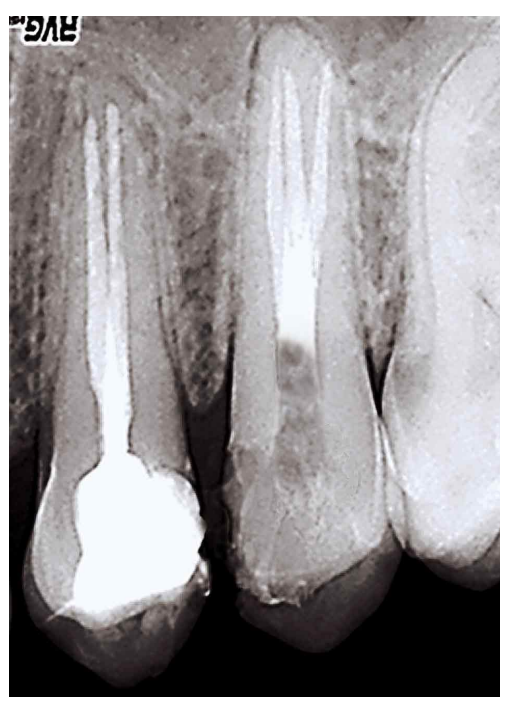

Fig. 2. Final radiograph observing the complete filling of root canals.

into the market new instruments designed with a special alloy to improve resistance to fracture. The special alloy improved flexibility and fatigue resistance (Gambarini et al., 2010; CastellóEscrivá et al., 2012).

The reciprocating motion is another new product introduced to 
the market with the novelty of root canal shaping with only one file, allowing clinicians to save time and cost (Dietrich et al.). This kind of instrument is subjected to a high rate of stress, therefore, it should have a good resistance to fracture (Kim et al.). The term reciprocating motion includes some angles and movements on the NiTi file, which will influence the performance and fail resistance. The above has relation with the low risk of fracture by torsion because the rotating angles are smaller than deflection angles (Gambarini et al., 2012). Some authors have supported the use of reciprocating motion, concluding that this system showed a higher duration of the NiTi instruments and, therefore, a higher resistance to fatigue when compared with the continuous rotatory system (De-Deus et al., 2010).

On the other hand, one of the reciprocating motion systems is the WaveOne, which shapes the canal by using a single file. Arias et al. (2012) exposed that "the use of a single file to shape the whole canal challenges the concept of an endodontic instrument not working for itself but rather preparing the canal for the following instrument". However, the same authors highlight the fact that the surface contact between the file and the canal increases. Therefore, the system was studied in vitro by some authors who describe some features. Goldberg et al. (2012) stated that this is a promising technique, with excellent results, regardless with the clinician experience and the canal anatomy. Berutti et al. (2012) reported that WaveOne is a simple system, which avoids risk of crosscontamination and is better able to maintain the original anatomy of the root canal with a lesser modification of canal curvature when compared with rotatory Protaper. Bürklein et al. (2012) concluded that root canal shaping with WaveOne system could be used with a good centering ability. Other authors as Kim et al., reported that this system is the most appropriate for constricted canal preparation due to its improved torsional strength. The WaveOne system presented a higher resistance to cyclic fatigue when compared with rotatory systems as Protaper or Twisted Files, by the fact that the first was submitted to less tensile and compressive stress (Castelló-Escrivá et al.).

The system cuts in a counter clockwise direction, allowing a great rotation angle in the cutting direction, achieving, as it progresses through the root canal, is engaging the dentine to cut, while the smaller angle is directed in opposing way allowing the file to disengage immediately and safely (Saber \& El Sadat). One important factor to consider is to avoid the overloading during the system using, to prevent risks as fracture, perforation or other problems (Goldberg et al.; Saber Sel \& Abu El Sadat).
The initial exploration to permeabilize the root canals with \#10 K-file is according to the proposal of Berutti et al. (2011). During the canal preparation with WaveOne rotatory system a glide path with a \#15 K-file was used as stated by some authors (Berutti et al., 2009; Saber Sel \& Abu El Sadat) to prevent NiTi rotatory file tip blockage. Also, the working length was checked throughout the procedure, even prior to preparing the apical portion of root canal, because it is expected to undergo a significant change in the working length as by Berutti et al. (2011). The working length was initially obtained by measure in the radiograph but supplemented with the electronic apex locator. This last point is very important to note because radiographic images have shown to be inaccurate in the correct determination of working length (Berutti et al., 2011); however, the aid of electronic apex locator showed to be a reliable and precise instrument to determine the WL in more than $90 \%$ of the cases (Gordon \& Chandler, 2004). Besides, another important factor to consider for the proper use of the WaveOne system is the speed. The manufacturers recommend the use at 350 rpm (Castelló-Escrivá et al.), which is in accordance with our methodology. Although there was little time spent in the canal shaping with this system, the time needed to reach the working length was higher than the 82 and 86 seconds reported by Burklein et al. and Dietrich et al., respectively.

Finally, it is possible to conclude that the WaveOne reciprocating file is a friendly and simple system that reduces cost, time and risk for the clinician, and which is also being recommended for novice students, regardless of the operator's experience.

ACKNOWLEDGEMENTS. DIUFRO project DI13-0008.

ARACENA, D.; BETANCOURT, P.; BORIE, E.; GUZMÁN, M. \& FUENTES, R. WaveOne: una manera simple y segura para lograr un tratamiento endodóntico. Un reporte de caso. Int. J. Odontostomat., 8(2):207-210, 2014.

RESUMEN: Las variaciones anatómicas de los canales radiculares juegan un papel importante en el éxito del tratamiento endodóntico, sobre todo en dientes con necrosis pulpar. Tradicionalmente, la preparación de los canales radiculares se realizó con el uso de limas de acero inoxidable, pero en los últimos años, nuevos instrumentos flexibles se introdujeron para evitar o reducir al mínimo errores o iatrogénias en la conformación del sistema canalicular. Se ha propuesto el movimiento reciprocante como alternativa al movimiento de rotación continua, con el fin de reducir el riesgo de fractura del instrumento y la deformación del canal radicular. El objetivo de este artículo fue presentar un caso clínico que describe una forma sencilla de realizar el tratamiento endodóntico de un premolar maxilar con tres canales radiculares utilizando el sistema reciprocante WaveOne.

PALABRAS CLAVE: endodoncia, obturación radicular, níquel-titanio, movimiento reciprocante, WaveOne. 


\section{REFERENCES}

Aracena, D.; Beltrán, V.; Fuentes, R. \& Borie, E. In vitro macroscopic and endoscopic analysis of three-rooted maxillary premolars and two-rooted mandibular premolars in the same individual: a case report. Int. J. Morphol., 30(1):19-24, 2012.

Arias, A.; Perez-Higueras, J. J. \& de la Macorra, J. C. Differences in cyclic fatigue resistance at apical and coronal levels of Reciproc and WaveOne new files. J. Endod., 38(9):1244-8, 2012.

Berutti, E.; Cantatore, G.; Castellucci, A.; Chiandussi, G.; Pera, F.; Migliaretti, G. \& Pasqualini, D. Use of nickel-titanium rotary PathFile to create the glide path: comparison with manual preflaring in simulated root canals. J. Endod., 35(3):408-12, 2009.

Berutti, E.; Chiandussi, G.; Paolino, D. S.; Scotti, N.; Cantatore, G.; Castellucci, A. \& Pasqualini, D. Effect of canal length and curvature on working length alteration with WaveOne reciprocating files. J. Endod., 37(12):1687-90, 2011.

Berutti, E.; Chiandussi, G.; Paolino, D. S.; Scotti, N.; Cantatore, G.; Castellucci, A. \& Pasqualini, D. Canal shaping with WaveOne Primary reciprocating files and ProTaper system: a comparative study. J. Endod., 38(4):505-9, 2012.

Bürklein, S.; Hinschitza, K.; Dammaschke, T. \& Schäfer, E. Shaping ability and cleaning effectiveness of two single-file systems in severely curved root canals of extracted teeth: Reciproc and WaveOne versus Mtwo and ProTaper. Int. Endod. J., 45(5):44961, 2012.

Castelló-Escrivá, R.; Alegre-Domingo, T.; Faus-Matoses, V.; RománRichon, S. \& Faus-Llácer, V. J. In vitro comparison of cyclic fatigue resistance of ProTaper, WaveOne, and Twisted Files. J. Endod., 38(11):1521-4, 2012.

Cantatore, G.; Berutti, E. \& Castellucci, A. Missed anatomy: frequency and clinical impact. Endod. Top., 15(1):3-31, 2009

Chakradhar Raju, R. V.; Chandrasekhar, V.; Singh, C. V. \& Pasari, S. Maxillary molar with two palatal roots: Two case reports. $J$. Conserv. Dent., 13(1):58-61, 2010.

De-Deus, G.; Moreira, E. J.; Lopes, H. P. \& Elias, C. N. Extended cyclic fatigue life of $\mathrm{F} 2$ ProTaper instruments used in reciprocating movement. Int. Endod. J., 43(12):1063-8, 2010.

Dietrich, M. A.; Kirkpatrick, T. C. \& Yaccino, J. M. In vitro canal and isthmus debris removal of the self-adjusting file, $\mathrm{K} 3$, and WaveOne files in the mesial root of human mandibular molars. J. Endod., 38(8):1140-4, 2012.

Favieri, A.; Barros, F. G. \& Campos L. C. Root canal therapy of a maxillary first molar with five root canals: case report. Braz. Dent. J., 17(1):75-8, 2006.

Gambarini, G.; Rubini, A. G.; Al Sudani, D.; Gergi, R.; Culla, A.; De Angelis, F.; Di Carlo, S.; Pompa, G.; Osta, N. \& Testarelli, L. Influence of different angles of reciprocation on the cyclic fatigue of nickel-titanium endodontic instruments. J. Endod., 38(10):1408-11, 2012.
Gambarini, G.; Testarelli, L.; Galli, M.; Tucci, E. \& De Luca, M. The effect of a new finishing process on the torsional resistance of twisted nickel-titanium rotary instruments. Minerva Stomatol., 59(7-8):401-6, 2010

Goldberg, M.; Dahan, S. \& Machtou, P. Centering Ability and Influence of Experience When Using WaveOne Single-File Technique in Simulated Canals. Int. J. Dent., 2012:206321, 2012.

Gordon, M. P. \& Chandler, N. P. Electronic apex locators. Int. Endod. J., 37(7):425-37, 2004.

Gutmann, J. L. \& Gao, Y. Alteration in the inherent metallic and surface properties of nickel-titanium root canal instruments to enhance performance, durability and safety: a focused review. Int. Endod. J., 45(2):113-28, 2012.

Javaheri, H. H. \& Javaheri, G. H. Comparison of Three Ni-Ti Rotary Instruments in Apical Transportation. J. Endod., 33(3):284-6, 2007.

Kim, H. C.; Kwak, S. W.; Cheung, G. S.; Ko, D. H.; Chung, S. M. \& Lee, W. Cyclic fatigue and torsional resistance of two new nickeltitanium instruments used in reciprocation motion: Reciproc versus WaveOne. J. Endod., 38(4):541-4, 2012.

Oporto, G; Fuentes, R. \& Soto, C. Variaciones anatómicas radiculares y sistema de canales. Int .J Morphol., 28(3):945-50, 2010.

Pedullà, E.; Grande, N. M.; Plotino, G.; Pappalardo, A. \& Rapisarda, E. Cyclic fatigue resistance of three different nickel-titanium instruments after immersion in sodium hypochlorite. J. Endod., 37(8):1139-42, 2011

Peters, O. A. Current challenges and concepts in the preparation of root canal systems: a review. J. Endod., 30(8):559-67, 2004.

Saber Sel, D. \& Abu El Sadat, S. M. Effect of altering the reciprocation range on the fatigue life and the shaping ability of WaveOne nickel-titanium instruments. J. Endod., 39(5):685-8, 2013.

Varela-Patiño, P.; Ibañez-Párraga, A.; Rivas-Mundiña, B.; Cantatore, G.; Otero, X. L. \& Martin-Biedma, B. Alternating versus continuous rotation: a comparative study of the effect on instrument life. J. Endod., 36(1):157-9, 2010.

Yared, G. Canal preparation using only one Ni-Ti rotary instrument: preliminary observations. Int. Endod. J., 41(4):339-44, 2008.

Correspondence to:

Daniel Aracena Rojas

Escuela de Odontología

Universidad Mayor

Temuco

CHILE

Email: draracena@gmail.com

Received: 08-11-2013

Accepted: 05-05-2014 